\title{
REVIEW
}

\section{On music and computability: Contrasts between Harry Partch's Bitter Music and Guerino Mazzola's Topos of Music}

\author{
Wilfried Allaerts \\ Biological Publishing A\&O and Immunology Department, Erasmus MC, Rotterdam, The Netherlands
}

\section{Check for updates}

Correspondence to: Wilfried Allaerts, Biological Publishing A\&O and Immunology Department, Erasmus MC, Rotterdam, The Netherlands;

E-mail: allae002@planet.nl

Received: September 24, 2021;

Accepted: October 11, 2021;

Published: October 14, 2021.

Citation: Allaerts, W. (2021). On music and computability: Contrasts between Harry Partch's Bitter Music and Guerino Mazzola's Topos of Music. International Journal of Arts and Humanities, 2(1): 44-55. https://doi.org/10.25082/IJAH.2021.01.002

Copyright: (c) 2021 Wilfried Allaerts. This is an open access article distributed under the terms of the Creative Commons Attribution License, which permits unrestricted use, distribution, and reproduction in any medium, provided the original author and source are credited.

\begin{abstract}
The clash of ideas between classical music and several avant-garde movements in the previous century, not only found its way into twentieth century musicology, it also led to a number of new developments in music digitalization. This paper reflects on the inscription of these opposing ideas about the concept of music into the contemporary views on the human condition and the notion of computability of human interactions. Harry Partch, the American iconoclast broke away from the classic, predominantly European traditions in music, and contested the abstract architecture and well-tempered tonal system of it. The mathematician Guerrino Mazzola constructed an even bigger, abstract formalization system, that allegedly allows for a complete digitalization of music, from the mind and inner ear of the composer towards the scores, the gestures and sounds produced by the performers up to the auditory cortex of the listeners. In this paper we will mainly investigate the philosophical and musicological basis of this formalization system, which is essentially based on the Denotator system and a number of concepts from algebraic topology applied to music. Finally, we will unravel the typical de-humanizing aspects that are followed in the digitalization system as used by Mazzola and what this approach implicates for humanity (and the human sciences).
\end{abstract}

Keywords: music, computability, digitalization, Denotator system, Topology of music

\section{Introduction}

The notion of correspondence between music and mathematics did not originate in the previous century. Neither was it invented by the great composer of the European Baroque period, J.S. Bach (1685-1750), nor is it just to attribute to him the epithets of 'founding father' of an esoteric number symbolism (van Houten \& Kasbergen, 1985) or wizard arithmetician (Hofstadter, 1979). The correspondence existed already in the antique Greek era of the Pythagoreans (ab 497 B.C.). Moreover, the Pythagorean theory of the 'harmony of the spheres' echoed in the medieval association between arithmetic, geometry, astronomy and music, that constituted the so-called quadrivium of liberal arts, that subsisted into the Middle Ages. So, the correspondence between music and mathematics is nothing new under the sun! The relatively new theory presented by Mazzola $(2002,2017)$, therefore has to be regarded as a novelty of methodology, rather than a brand new idea of correspondence between music and mathematics.

What is especially new in the second edition of Mazzola's encyclopedic book, apart from the much bigger size than the original work, is the elaboration of its topological basis, taking benefit of Grothendieck's (1971) (topos) theoretic algebraic geometry and Galois theory of concepts (in the sense of denotators as circular definitions of concepts) (Mazzola, 2017). Using these mathematical tools, Mazzola not only succeeds in providing an abstract, formal system for concept classification (with the necessary properties of 'uniqueness', 'recursiveness' and 'completeness'), it also forms a rigorous basis for digitalizing the concept system. Of course, and especially after the several periods of lockdown after the new pandemic, we all have - at least in some intuitive sense - a firm apprehension that a music registration (digital or otherwise) and the 'real' thing of a music performance, are not the same thing. But before to proceed with Mazzola's mathematical construction and programming language (that even extends to the realm of music performance), we want to have a clear view on what music entailed between humans, in a time before computers and digital computing were an ubiquitous element of our environment.

The origin of digital computing forms a bewildering turning point in the history of humanities. In the decades before the famous Alan M. Turing (1912-1954) constructed a device that was capable of breaking the ENIGMA code and paved the way to the first post-war computer 
(Hodges, 1983, 2000), an American composer, Harry Partch (1901-1974), broke away from western (and especially European) music (Partch, 1940-1969, 1991). Harry Partch was one of the first great musical iconoclasts and became an important inspiration for composers like Aaron Copland (1900-1990), famous for compositions like the Fanfare for the Common Man (1942), John Milton Cage (1912-1992), among other things the pioneer of the 'prepared piano', Frank Zappa (1940-1993), iconoclast par excellence (Winter, 2021), and many others.

Also other modernist composers in the nineteenth century broke away from the classical tradition of western music, like Arnold F.W. Schoenberg (1874-1951), Karlheinz Stockhausen (1928-2007) or Charles E. Ives (1874-1954). But in contrast to the previous, Partch abhorred the labels of avant-garde or revolutionary composer (Partch, 1991). He also renounced the so-called international modernism of Schoenberg and disciples, or the modernism of Igor Stravinsky (1882-1971), neither did he strive for a characteristically American strain of the European traditions like Ives had generated (Partch, 1991). Harry Partch, however, didn't gain from the celebrity of his contemporaries, partly because he composed his music on his own, unique instruments. Following a visit to New Orleans in 1930, Partch burned fourteen years of his compositions in an iron stove and so, irrevocably broke with his own and European musical tradition (Partch, 1991). The reasons for this radical break was his rejection (from 1923 onwards) of the twelve-tone equal temperament system (introduced since J.S. Bach wrote (Das Wohltemperirte Clavier) (Bach, 1722) and his adoption of the 'principles of just intonation' (Partch, 1991). As a consequence, he had to invent new musical instruments to bring his musical principles into practice. Finally, he devised an unique 29-tone and later 43-tone-to-the-octave scale of music and, probably more importantly, he sought to achieve a perfect balance of poetry and music.

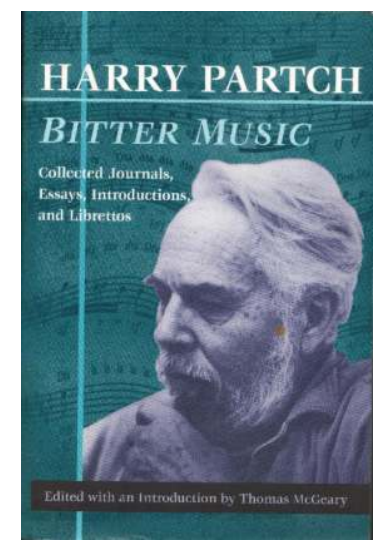

Figure 1 Photograph of front cover of the first paperback edition (2000) of Harry Partch's collected works 'Bitter $\mathrm{Mu}$ sic', edited and introduced by Thomas McGeary, University of Illinois Press, Chicago. (Frontispiece photograph showing Harry Partch in Los Angeles, 1966)

The provocative ideas of Partch on music and poetry especially emanate from his essays 'Bach and Temperament' (1941) and 'W.B. Yeats' (1941), written long after Partch's encounter with the illustrious Irish poet William Butler Yeats (around 1934-1935). His chronicles from the thirties and forties, entitled Bitter Music (1942) and romanticized as Partch's 'hobo period' (reflecting not only the Depression years, but also his own personal 'Great Depression'), became published posthumously. Thanks to a grant from a federal agency (NEH, USA) and through the assistance of philanthropist Betty Freeman (1921-2009), the University of Illinois disclosed Partch's collected journals, essays and other works, and made them accessible, resulting in the remarkable compilation Bitter Music (Partch, 1940-1969, 1991). (see Figure 1)

Beside its contribution as a biographical document, contributory to the American Depression literature, his writings contain valuable theoretical viewpoints about acoustics and just intonation. But, in the words of Thomas McGeary (Introduction to Partch (1940-1969, 1991)), Partch's legacy and significance for the twentieth-century "arises from his still provocative ideas about music and its place in human culture" (p. xvi). It is exactly this place of music in human culture, that has inspired me for the present study on the correspondence between music and mathematics. In this paper, we will not only try to unravel the topological machinery, explaining Mazzola's translation of music semiotics (Mazzola, 2017) into a 'well-tempered' object-oriented programming language, but also we will pay serious attention to objections from Partch and others. Moreover, we will forward the question regarding the role of digitalized forms of communication in concept formation, language and intersubjective, human relations. Herewith, we link up with previous studies on the role of music and other forms of sense utilization in human communication (Allaerts, 1992; Allaerts, 2019, 2020). 


\section{Partch on Bach, Temperament and Poetry}

In his essays, musicologist Harry Partch calls the influence of J.S. Bach on western music tradition a double shadow : the first 'shadow', according to Partch, results from Bach's changing of the tone intervals (compared to the preceding tradition), making them 'well-tempered'. Partch disagrees with the equalization of all tone intervals and will create an unique intonation system involving a 43-tone-to-the octave scale. The second 'shadow' results from reducing the human voice to a mere instrument of the music, hereby banning out the tradition of poetic declamation (Partch, 1940-1969, 1991). Partch has juxtaposed both essays, Bach and Temperament and W.B. Yeats, both written in 1941, as a strong contrast between the abstract, ingenious harmonical architecture of Bach's music (e.g. Das Wohltemperirte Clavier) (Bach, 1722) and the - typically Irish - rebellion against the "abstraction and symphonic complexity" in classical music and poetry. After an encounter with W.B Yeats in the thirties, both agree that 'pure' poetry can only be approximated by Irish music, using a minimal number of instruments, say a fiddle and a drum or only the human voice, as well as other, non-western forms like the Japanese Noh and Kabuki traditions (Partch, 1940-1969, 1991). It is interesting to note that these examples, both poetry and Japanese Noh theatre art, are also used by Mazzola in his arguments (see Par. Mazzola's notions of concept of music and semiotics) for a digitalized encyclopedic concept system of music.

Partch's criticism is in fact astonishing, especially for the millions of people that found comfort and joy in listening to or participating in performances of music composed by Bach But the imputations against the work of Bach or negative connotations about classical music, also in the 'elitism' remark of Mazzola (see below), are not very different from - for instance - the villainous rebuttal or furious tirade of the philosopher Friedrich Nietzsche (1844-1900) against the music and person of Richard Wagner (in Der Fall Wagner) (Nietzsche, 1988). Or not fundamentally different from the remarks of Schoenberg, the inventor of the twelve-tone system, stating that Wagner's contemporaries (including also and especially Friedrich Nietzsche) didn't grasp the complicated tonalities in Wagner's music (Schoenberg, 1954, 1969). Under the present-day vigor of social media, the personal approval or disproval of a certain music tradition is of minor importance compared to the criticisms, opinions as formulated by media or influential authors. Casting a shadow over a public figure, however, isn't philosophically as interesting as casting a shadow over a form of human culture (poetry, classical music, or even mathematics), because it exemplifies the thoughts about typical aspects of the human condition. Following the dictum ascribed to Nietzsche, that "without music, life is (would be) a mistake", we will explore the argument that a de-humanizing approach of music inevitably has a far-reaching impact for the view on humanity (see Par. Digitalizing music as an essentially de-humanizing process). The following paragraphs on Mazzola's view on the mathematical correlates of music concepts, moreover, will appear exemplary of Mazzola's thinking about human communication, consciousness and psychology.

\section{Mazzola's notions of concept of music and semiotics}

In order to firmly ground an ontology of music, Mazzola does not choose to start "from the whatness as a Kantian 'Ding an Sich' ", but from "how we conceive music?" (Mazzola, ibidem, p. 21). Since a concept in Kant's terminology is "a topos, a logical place", the question of the concept of music involves "a topos in a particular "concept space' ", referring to the "ontological fundus", i.e. the Platonic idea living in an "hyperouranios topos" (Mazzola, ibidem). By choosing this philosophical, conceptual reference point, and not the topographical characterization of music as 'essentially' taking place in the passing or 'betweenness' of time from one moment to another (Allaerts, 1992; Zuckerkandl, 1957; Escher \& Escher, 1985), Mazzola also chooses a distinct philosophical framework (see below). Doing so, Mazzola avoids certain so-called 'breviloquent' but 'topographically blurred' concepts like those expressed by Heinrich Eggebrecht (Eggebrecht, 1993, 1996) in what Mazzola calls a "most dramatic breviloquent repression strategy". The problem of subjectivity, according to Mazzola, follows from Eggebrecht's ontological description of music as residing in the "I" (Mazzola, ibidem, $\mathrm{p}$. 22). Mazzola attaches a great importance to the reputed viewpoints of his great examples like Eggebrecht and also Dahlhaus (Dahlhaus \& Eggebrecht, 1985), who are put aside in a defaming way as old-fashioned authorities. But in contrast to Mazzola, we previously attached great value to the concept of 'simultaneity in music' like defended in Dahlhaus musicology (Allaerts, 1992).

In the viewpoint of Mazzola, the localization of musical existence is due to the "interweaved usage of topographically distinct locations in the classical ontological discourse" (Mazzola, ibidem). These distinct locations, according to Mazzola, refer to the three intrinsic, ontological 
coordinates, namely the coordinates of (I) Reality, (II) Communication and (III) Semiosis. We will further try to explain that this approach is a difficult, contorted route to replace twentieth century existentialist philosophy of the human mind by the older, more trustworthy, essentialist philosophies that dominated western thinking since Platoon and Aristotle (see also Allaerts (2017) for Tillich's analysis of the essentialist take-over in the heritage of Adorno and the Frankfurt School).

Following the three distinct levels of so-called local topography (see above), Mazzola arrives at a so-called cube of $3^{3}=27$ distinct topographic locations, namely: the topography divided in (A) 3 Layers of Reality: the physical, mental and psychological layers; divided in (B) the 3 roles of Communication: the role of creator, work and listener (referring to Molino's Communication Stream) (Molino, 1975), and finally, in (C) the 3 aspects of Semiotics: the significant, signification and significate. The latter division follows Roland Barthes' (1915-1980) generalization (Barthes, 1964) of the linguistic theory of Ferdinand de Saussure (1857-1913) and André Martinet's elaboration of the 'Principle of Reference' (Martinet, 1960).

Although some of these theoretical works (on linguistics, etc.) may seem outdated for younger generations of readers, Mazzola's huge, encyclopedic work fills with awe. But, at the same time, it is a colossal obstacle, casting a massive, rather intimidating shadow that by far exceeds the shadows of J.S. Bach, that according to Partch, have darkened the subsequent eras of classical music (see Par. Partch on Bach, Temperament and Poetry).

One very important, positive merit of Mazzola's analysis is the recognition of the differences between music and linguistics, and especially the non-linearity of the musical 'syntagm' (being the juxtaposition "in a chain or network of signs in successive contiguity"): "Whereas (a) linguistic syntagm is one-dimensional (in time), the music syntagm extends simultaneously in several dimensions" (Mazzola, p. 16). To further corroborate this non-linearity notion and also in order to understand the concept of musical score, we here refer to our previous analyses (Allaerts, 1992, 2019), making use of the Bergsonian (1859-1941) concepts of duration and simultaneity (Bergson, 1968), as well as Dahlhaus' notions of simultaneity and consonance (Dahlhaus, 1962). Mazzola's system not only allows for an incorporation of the specific, musical semiotics as an independent ontological co-ordinate system, it also allows a far-reaching mathematical translation of this semiotic 'machinery'. Moreover, it forms an indispensable (not missing) link for digitalizing music in the realm of a (fully) computerized world. We will further elaborate on the consequences of this digitalization process for the humanities (in Par Digitalizing music as an essentially de-humanizing process).

Concerning the objections of Partch and the examples of experimental Japanese theater and music forms (like the 'Noh and Kabuki'), Mazzola points to the existence in the music of Noh theater of "different score instances, e.g. for vocal utai music denoted in melodic units (fushi) to the right of texts, or for the hayashi notation systems for flutes and drums" (Mazzola, ibidem, p. 13) (Komparu, 1983). However, semiotics based on the 'lexical reality' alone is not enough, for Mazzola recognizes the importance of "the special class of 'shifter' or 'deictic' signs" in music, transcending the lexical reality. Namely, these signs referring to the notions "I", "now" and "here", cannot exist with a 'marginal' lexical part of the system, Mazzola explains. "On the contrary, a rich deixis cannot succeed with a rich lexical support. It is evidently a difficult business to 'hit' the unsayable by use of an arsenal of lexical approximation pointers" (Mazzola, ibidem, p. 16). For the non-familiar readers, 'lexical' is derived from the Greek word $\lambda \epsilon \kappa \tau O \nu$, which in the stoic tradition refers to a system of 'sayable things' in contrast to the 'real' things or to the psychological imagination. Here, it would be interesting to note the difference (in linguistic theory) between the 'real' object and the noun referring to it, to start with Hegel's (1770-1831) notion of symbolization and mediation (Allaerts, 2019). However, the interpretation of these Hegelian notions in the twentieth century philosophies of for instance Jacques Lacan (1901-1981) or Slavoj Žižek ( ${ }^{\circ} 1949$, Ljubljana, Slovenia), although most fertile philosophical sideways, would definitely detract from the readability of the present analysis.

The other objection of Partch, namely the simplicity of poetic declamation (see Par. Partch on Bach, Temperament and Poetry), is overwhelmed by a technical reading of poetry following the definition of Jakobson's Poietic function (Jakobson, 1960). Despite Mazzola's avoidance of certain 'revolutionary forms of artistic performance', and the inclinations of some to link up poetry with quantum physics and even with string theory (Dutch Physics Society, 2021; Mazzola, 2017), we are inclined to avoid the digressions into the realms of both experimental poetry and speculative forms of postmodern physics (Ellis \& Silk, 2014) for obvious reasons: the mer à boire of Multiverse and String theories and the rich kaleidoscope of postwar modern art and poetry forms, would not fit into a normal-sized paper. Moreover, it isn't clear whether the digressions into exotic theories in physics aren't a way to elicit an aura of pseudo-scientific literacy or postmodern extravagancy. How to evaluate their scientific status without going into a full-depth debate of the state-of-the-art of Multiverse cosmology, Quantum physics, String 
theory and others? (Mazzola, 2017; Ellis \& Silk, 2014)

Mazzola's choice not to start with the diachronic analysis of music semiotics, i.e. the historical analysis of musicology and music semiotics in a changing world, has a price: it creates an instrument of pseudo-objectivity that may seem useful to avoid the difficult philosophical traditions of phenomenology, existentialism, (post-)structuralism,.. But also the non-western philosophical traditions aren't taken seriously. Philosophically, this tendency towards pseudoobjectivity has to be regarded as a restorative or even reactionary movement. A return to music as a scientific, mathematical 'objectivity' cannot be seen without casual reference to the postwar avant-garde movements, like the movements (in music) of Partch, Cage, Zappa and parallel movements in art and poetry. However, it follows from the de-humanizing characteristics of the digitalization process in itself, that the mathesis universalis applied to music, forwards the urgency of this discussion for the post-millennial generations of humanity.

The recent public awareness of a catastrophic evolvement of the present pace of climate change, not counteracted by appropriate measures of the ruling governments, has resulted in an abhorring of a purely technical, local approach and so-called ad hoc natural philosophy. An esthetic or mystical revival of ecophilosophy, taking distance from the classical philosophical traditions has been proposed as a valuable alternative (Libbrecht, 2001). Because the economic and technological developments haven't protected the planet's climate and ecosystems, the methodologies, disciplines and philosophies subsisting these developments are distrusted and repudiated (Allaerts, 2020). This forms a problem for any explanatory system based on the idea of mathesis universalis, at least according to André Glucksmann (1937-2015): "Language will never attain the universality of mathematics, like in the dreams of the philosophers after Descartes and ending with the mathesis universalis; mathematics on the other hand will be submerged in language and take benefit from the bivalent, insurmountable universality of plain language, of which Platoon said it makes everything floating. Therefore, if the master wants to be successful in mathematics, he has to drown himself in (plain) language..." (Glucksmann, 1977). With the risk of drowning in too lengthy texts, in the following paragraph, we will try to explain the essential mathematics used by Mazzola, namely the denotator system (Par. Mazzola's drivers: the Denotator system).

\section{Mazzola's drivers: the Denotator system}

In order to cope with the 'universal encyclopedic characteristics' of a universal data system, namely the characteristics of 'unity', 'completeness' and 'discursiveness', Mazzola introduces his 'denotator system' (Mazzola, 2002, 2017). Following the original German work preceding his 'magnum opus' (Mazzola, 1990) and the development of the composition software and platform system presto ${ }^{\circledR}$ (Mazzola, 1989-1994), since the early nineties, several improvements of the original framework have been performed. This happened especially with the help and criticism of the data model, analysis and performance platform RUBATO® (Mazzola, 2017).

\subsection{Naïve exposé}

What Mazzola himself calls a 'naïve approach' to denotators follows from the combination of a 'recursive definition of the form-space' with the substance points defined, based upon this concept, denoted in a triple way, namely:

$$
\text { Form-Name } \rightarrow \text { Type (Coordinator). (6.1)(Mazzola, ibidem, p.43) }
$$

The Form-Name corresponds to any character string marked by quotation marks (" '), the Type is either compound or simple, the Coordinates are for instance the set \{Onset, Pitch, Duration, Loudness $\}$. The compound types are also called ramification modes, referring to a STRING (character strings, like ASCII characters), BOOLE (Boolean elements 0 and 1), INTEGER (set of 'Integer' numbers, $\mathbb{Z}$ ) or FLOAT (floating point set, i.e. $\mathbb{R}$ set of 'decimal' numbers, which in fact should be called 'Rational' numbers, $\mathbb{Q}$, in contrast to the 'Real' numbers $\mathbb{R})$.

Doing so, Mazzola has created an encyclopedic system (called the 'pointer character') comparable to object-oriented programming (Mazzola, ibidem, p. 48) - that also meets with the demands of (non-)circularity (the recursive regression needs to stop at a completed specification of the denotator) (p. 49), as well as the demands of unity and completeness. The unity is jokingly called the 'yoga of pointers' (referring to the 'unity' term as used in many, especially westernized versions of the yoga discourse). The 'completeness' claim follows the "rigorous formal setup" based on the most general mathematical construction principles (products, coproducts and 
power-sets), together with the "epistemological factotum of synonymy" (Mazzola, ibidem, p. 49). 'Synonymy' indeed is also a type construct to rename a denotator. "Besides a renaming of the space and the point, nothing really happens - unfortunately, this is a very common situation in the humanities". This sneer is indeed characteristic for a certain contempt of the humanities or human sciences, but the objectification as method of palliation works: "Notice, however, that synonymy is not symmetric, i.e. the new denotator is recursively later than the old one. This is essential for understanding the construction history of concepts" (p. 47). This seemingly rather unimportant side-marks in the argument of Mazzola recalls an analogy with the Duck-typing methodology (referring to the saying of the Hoosier poet, James Whitcomb Riley [1849-1916], "When I see a bird that walks like a duck and swims like a duck and quacks like a duck, I call that bird a duck"). The expression was also followed by the philosopher Hilary Putnam (1926-2016) in the so-called 'Twin Earth (thought) experiment' (Putnam, 1975) and since decades became standard practice in object-oriented programming languages.

In contrast to common practice in computer programming, the Duck-typing methodology has profound effects in the remaining part of the 'humanities', as wittily denoted by Mazzola (see above), to start with the withering influence of etymology. In a more derived sense, it also leads to the diminution of practical contextual information of foreign languages, like discourses 'lost in translation', especially the fate of threatened or nearly extinct languages (Allaerts, 2020). Moreover, and a fortiori in the deeper philosophical understanding of the 'paronymia' of words and symbolization in linguistics following Ernst Cassirer (1874-1945), it completely overwrites the historical layers of semantics and etymology (Cassirer, 1946; Allaerts, 2019).

To settle with possible criticisms of this programming approach, already at the onset of his magnum opus, Mazzola renounces to the hermeneutics of a historical, diachronic linguistic of music (such as it is common in diachronic linguistics) (Mazzola, ibidem, p. 6). Moreover, following the gathering of every aspect of social psychology, socio-semiotics and pedagogical problems (sic) (like in music education) into the collective bin of 'psychology', there is no further obstacle in the objectification needed for a digitalization approach. Regarding a possible, tiny escape from the completeness claim, Mazzola argues that even an ethnological pitch-related form', which has "not yet been made fully explicit and is merely 'sketched' in a simple STRINGtyped form of unknown pitch type" (p. 49), does not evade the problem of reductionism, and worse, does not at all remove the taint of .. supremacy.

In the following section, it appears that mathematical objectification is indeed the key for defining a fully digitalized smart address system (see below).

\subsection{Functors, Circular Denotators and Prime number calculations for smart address systems}

The 'Functor' notion, derived from Algebraic topology, offers a methodology to denotate or transfer one system or set of spaces to another system, keeping the structures invariant (like topological spaces, groups, ordering...) (Reinhardt \& Soeder, 1980; Allaerts, 2019) and therefore is well suited for Duck-typing transfer of information (see above). Mazzola uses the 'functor' notion $[\mathrm{Fu}]$ to identify the space or domain of a 'form' $(\mathrm{F})$, which in the naïve exposé was shown to be associated with the Form-Name (see formula 6.1 above), but in the full notation is represented by the quadruple: $\{$ name of $F[N F]$, type of $F[T F]$, coordinator of $F[C F]$ and identifier of F [IF] $\}$ (Mazzola, ibidem, p. 54-55).

The difference with the naïve setup is that now an identifier is added in order to avoid the problem that "many equivalent modules or higher constructs (functors) may intervene" and to integrate them without "losing their structural identification" (Mazzola, ibidem, p. 56). The argument is analogous to the problem of higher order ( $2^{\text {nd }}$ order and higher) Predicate calculus (the branch of Symbolic logic that uses "symbols for quantifiers and for subjects and predicates of propositions as well as unanalyzed propositions and logical connectives", to be discerned from Propositional calculus) (Woolf et al., 1981), which according to Reinhardt and Soeter (Reinhardt \& Soeder, 1980) results in the problems of incompleteness and indecisiveness of $2^{\text {nd }}$ order Predicate calculus. Another analogue is found in A.M. Turing's quotation regarding Ordinal logics, namely that "completeness is incompatible with invariance" (Turing, 1939), although one should also consider the later extensions of Propositional calculus, that Turing made in his contributions to Type theory (Allaerts, 2020).

From this identifier anchor onwards, forms can be logically anchored in modules. Hereby, Mazzola takes benefit of the axiom of the excluded third, following Paul Finsler's (1975) dictum that "an object's existence is equivalent to the possibility to think the objects without provoking any contradiction to classical principles of logic: identity, contradiction, and excluded third" (p. 57). The 'excluded third' means the excluded union of a proposition and its contradiction, or 
so-called exclusion of paradox. The choice of modules (Mod) allows for 'recursive foundations of forms in simple spaces' (p. 59); if a definition does not terminate on the level of simple forms, it is called a circular form (opposed to regular forms) (p. 64). Two examples of the possibilities to build modules from the direct sums of modules (corresponding to products of simple forms) are the coordinator $\mathbb{Z}_{n}$ "denoting the pitch classes in n-tempered tuning" and $\mathbb{Z}_{m}$ denoting "the $m$-cyclic metrical onsets" (Mazzola, ibidem, p. 63). Without going too much into the mathematical or topological details, we retain that Mazzola positions pitch and motivic points on a typical topological body, the torus: "the coordinator of the combined form $\operatorname{Mod}_{m, n}$ positioned on a torus, denotes a type of motivic points". This corresponds to what is called motif-analysis in musicology, which, according to Mazzola, shows some 'algebraic' connection of onset and pitch data, as represented by the self-addressed denotator:

$$
S(f): \mathrm{Z}_{m} \oplus \mathrm{Z}_{n} \rightarrow \operatorname{OnPiMod}_{m, n}(f) \quad \text { (6.44)(Mazzola, ibidem, p.63) }
$$

For the correspondence between pitch, tonal key and circular motifs, see also the circle of fifths and its use in Bach's well-tempered compositions (Hofstadter, 1979).

Mazzola is somewhat reluctant to link up with certain "mathematical structures used by certain composers, like aleatorics by John Cage, Fibonacci numbers with Karlheinz Stockhausen, or fractals with Mesias Maiguashca" ( ${ }^{\circ} 1938$, Quito, Ecuador), because "it cannot be decided $a$ priori which mathematical structures carry musical meaning" (ibidem, p. 59). The framework built by Mazzola therefore has to be regarded as 'formal frame' for the presently available empirical material. Or, it is a purely objective formalization system, to be used in music digitalization and not relating to mathematical, cultural or other insights.

In order to perform an ordering system (see also 4.3 Non-linearity of coding system versus pseudo-linearity), a procedure of 'flattening' of the macro-event (of a musical object) into the mental onset-pitch domain has to be performed. Without going into the full depth of his analysis, this procedure allows for the ordering of forms and denotators. These orderings are called 'linear and partial', and are considered fundamental in 'defining receptive navigation tools' (p. 75). The navigation tools are considered essential for "representation and retrieval problems of general musical objects" (p. 75), and therefore, primarily result from the problem of navigation and retrieval of objects in digital data systems, rather than from the nature of music as an intersubjective, social phenomenon.

From the concepts of linear and partial ordering toward a smart address system for "categories as point spaces which are sorted and structured by addresses", not only seems as a small step for the cursory reader (but a giant step for humanity), it also involves a vast number of so-called 'local theory', topological terminology and even prime number calculus. Even the experiences of singing with 'brilliance', with vibrato or simply 'singing out of tune' (inharmonicities) may be subjected to hierarchical ordering systems, according to Mazzola, although one should correct the erroneous, one-dimensional hierarchical system of inharmonicities as developed by Lerdahl (Lerdahl, 1987). Doing so, the sorted, modular address system of Mazzola allows for "grasping (even) the blurred and ambiguous concepts in musicology" or "making the vague precise" (p. 241). This emphasizes the powerful topological tools for technical classification but also its value in the semantic analysis of reality at the three levels described (mental, physical, and psychological). However, a global view is missed, according to Mazzola, for instance as exemplified in the notions of musical manifolds and musical variety, for which purpose Mazzola further developed a 'global theory' on musical and mathematical manifolds (Mazzola, ibidem, p. 245-372).

\subsection{Non-linearity of coding system versus pseudo-linearity}

The notion of non-linearity of the musical realities - mentally as well as following the simultaneity of sounds in a (dis)harmonical score or performance - has been recognized by several authors (Allaerts, 1992; Zuckerkandl, 1957; Escher \& Escher, 1985) and also on multiple occasions, is defended by Mazzola (see above, e.g. criticism of Lerdahl's hierarchical system). The problem of finding an ordering system with a unique, retrievable address system, however, requires a serious effort to restore the linearity in the coding system. In the first part of his encyclopedic work, Mazzola makes use of several methods of linear ordering (ordering on product type, coproduct or powerset): in plain language this ordering may correspond to respectively the linear ordering of notes in a score, the ordering from low to high pitch (corresponding also to the alphabetic ordering of the letter names of notes, $\mathrm{E}<\mathrm{F}<\mathrm{G}$ ) or the absence or presence of a subset of notes in a certain set (following the rule that $\mathrm{S}$ is a subset of $\mathrm{T}$, if and only if:

$$
\operatorname{Max}(S-T)<\operatorname{Max}(T-S) \quad(\text { Mazzola, ibidem, } p .52) .
$$


Following these linearization procedures, the music score can be completely ordered in what we call a pseudo-linear, coded system, or the coding transforms a non-linear process into pseudo-linearity. Essentially, this is our main criticism of Mazzola's topology of music: the digitalization into a proper data retrieval and representation system results into pseudo-linearity (in retrograde order with respect to the creative activity of the composing artist), thanks to a pseudo-linear ordering of the music score. As Mazzola points out, a similar statement could be made of the retrograde analysis of the music performance or psychological experience of the listener, although without the music score being actually present during live performance or esthetic revival. Even with the difficult, non-invertible rhythms of Olivier E.P.C. Messiaen (1908-1992) and other postmodern musical landscapes with extra-ordinary symmetries like in the serial techniques used by Stockhausen, Mauricio Kagel (1931-2008) and Pierre Boulez (1925-2016), a "structural paradigmatism of musical gestalts wherein hitherto separate musical parameters become freely interchangeable" (Mazzola, ibidem, p. 127), opens a route for further parametrization and objectification. We will not dwell into the topological hyper-particularities of Mazzola's categories of gestures, hyper-gestures, gestalts and models of creativity (including the Hegel Concept group and Hegel Body in the Concept Architecture of Forms and Denotators) (Mazzola, 2017), because it may probably become a lifetime achievement to respond to them in a discourse that can be understood by an audience that is big enough to exceed the number of elements in the set $\{$ authors + responders $\}$.

\subsection{Digitalizing music as an essentially de-humanizing process}

This paragraph is not about the socio-economic effects of digital recording practices, neither on the economic impact of the digital music industry (or the effect of the Internet on various carriers or digital record systems), neither about the benefits or scourges of disruptive innovations caused by software developers and/or electronic devices in the present practices of music composition. It is also not about the global trend of storing all products of human creativity in the cloud of digitalized information, although the socio-economic effects for the creative professions of giving up individual rights such as copyright ownership, is a very interesting subject that merits the ocean of time and efforts to pursue them.

We added this paragraph to the analysis of Mazzola's work, because in his work, he clearly shows how de-humanization exactly works. This is not only interesting for the realm of music Moreover, it surpasses the metaphorical discourse of the unstoppable advance of the artificial over the biological, such as the oblique reference to G.W.F. Hegel's (1770-1831) 'mechanical memory' (see above). In twentieth century philosophy, it became common heritage that the human senses are to be mistrusted. Of course, we all know that human vision doesn't give a 'perfect' representation of the 3D-world, neither are the human ear and auditory centers in the human brain capable of 'perfectly' representing the acoustic signals travelling in space, e.g. when we listen to music or to sounds altogether. "The ear fails as a metonymy of cortical music processing: there is a huge transformation process between the auditory cortex and the ear's cochlear system" (the sense organ that actually receives the acoustic signals) (Mazzola, ibidem, p. 14). For Mazzola, the (human) ear is a phantom! Mazzola uses this argument to counter the criticism of subjectivism as forwarded by Eggebrecht (see Par. Mazzola's notions of concept of music and semiotics). For the human vision, many experiments indeed have demonstrated the limitations and susceptibility to visual illusory perception. The same holds for the auditory perception, so, Mazzola has a point here.

On the other hand, in an a capella choir, the singers are advocated to listening to one another, in order to create a common, unison tone, each individual voice coloured according to the others: the absolute pitch is less important, but without listening, unison singing is impossible.

Another technical approach is used to describe the experience of performing. According to Mazzola, this results from an encapsulation and retrograde reconstruction or decoding of a music performance by the listener. This follows from the problem of not hearing the 'contrapuntal construction' during the process of composition (or performance). Doing so, the uncertain, 'problematic' process of creation, the trial and error, is replaced by the symmetry of the esthetic consumption of a performance gesture. The latter is seen as an end product, the ideal performance that is constructed in a retrograde procedure (Mazzola, ibidem, p. 14).

But doesn't it belong to the basic characteristics of the human condition not to be as perfect as a machine, robot or as whatever lifeless artefact of technology? For the existentialist philosopher Jean-Paul Sartre (1905-1980), music could re-mind us of the "existence of another time" (causing the stealthy escape from the Nausea as the primary entrance to the "here and now' of self-consciousness) (Allaerts, 1997). Despite the objections or shortcomings of the phenomenological philosophies of time, Sartre and many others have pointed to the importance of the notion of passing of time and the inter-subjectivity of the musical experience. 
Moreover, the global crises caused by the COVID-19 pandemic have convincingly illustrated, even more convincingly than any philosophical discourse, that how perfect the online, remote computer-based (telematics) tools may be or become in the future, they reveal a fundamental, missing link between listeners and performers of music. The long period of lockdown has been called a disaster for professional and amateur musicians, an experience corroborated by numerous artists. But not only the performing artists have missed their audience, also the public awareness nowadays is giving support to the importance of the experience of listening and being together in real-time. 'Connecting to other people' is the utmost characteristic of being human, that's what is often heard, after people have been struck by a terrifying incident. Social grooming cannot be reduced to social networking on the Internet. The invention and construction of Second Life marketplaces or other digital trends in the construction of virtual worlds (in the first decade of the new millennium), did not alter this fundamental need. And apart from its initial and catastrophic impact on the global population, the corona pandemic has revealed that the unifying power of sharing a common experience, such as a piece of music, cannot be replaced by whatever technological improvement or surrogate of the 'real thing'.

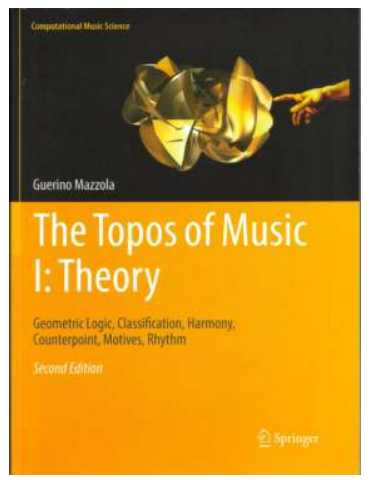

Figure 2 Photograph of front cover of first volume of Guerino Mazzola's Topos of Music (2017, 2nd Edition). Note the allusion to Michelangelo's Creation of Adam in the top figure.

But still, there must be a reason why some keep on putting so much effort in de-humanizing what is so characteristic and natural for the human condition. Even the famous painting of the Creation of Adam by Michelangelo (in 1508-1512), a fresco picturing on the ceiling of the Sistine Chapel in the Vatican, and deformed by Mazzola on the cover page of his book (see Figure 2), shows the purpose of the project: it replaced the human figure in Michelangelo's fresco by a mathematical construction. The reference of this cover picture is a literal defamation of the human aspect in Michelangelo's Creation of Adam. Obviously, such a gesture is meant as food for thought: why do we need humans, if mathematics can do a better job? Of course, we wouldn't support the hubris of a thought of this kind, simply because also the mathematics are a product of the human mind, and of human culture. Does mathematical abstraction always result in the creation of 'perfection'?

The question of the meaning of perfection in music and art is legitimate, but another question is more important: why does it matter? The deeper reason in processes of de-humanization are to be found in the rather ugly regions of the human motivators: segregation and supremacy of a certain elite, monopolization of a sector of the digitalized world, commercial profitability... Examples are easily found among the dominant players of the world, where a digital platform excludes the participation of alternative, competitive software suppliers. Mazzola uses the 'elitism' blame in a casual reference to certain traditions of classical music performance, but how to get inside a mathematical stronghold? Mathematical elitism may seem a strange phenomenon for readers that are completely devoid of any form of mathematical literacy. However, the text fragments aiming at keeping out unwanted trespassers are one of the most curious aspects of mathematical literature. Often it is used as a warning for biologists because they are known for 'spoiling' the mathematical purity and beauty of mathematical reasoning: they spoil the argument by contamination of the discourse with biological trivialities originating from living experience. Or, in the words of Mazzola: "Those who insist on the dogma that precision and beauty contradict each other, and that mathematics only produces tautologies and therefore must fail when aiming at substantial knowledge, should not read such a book" (Mazzola, referring to his own book, preface, ibidem, p. x). This quote illustrates our point about the 'imperfection' of the human senses. We leave the argument regarding the 'beauty of/or versus perfection' to our readers judgement, but, we are not opposed to the idea that also mathematics may produce substantial knowledge, even at Wittgenstein's (1895-1951) 'extremes' of the mathematical paradoxes and tautologies (Wittgenstein, 1922). 


\section{Concluding remarks: the Promethean saga revisited}

In the present paper, we started a philosophical analysis with a remarkable musicological figurehead that marked a turning point in the twentieth century history of music: the critical writings of Harry Partch, as collected in the posthumously published collection Bitter Music (Partch, 1940-1969, 1991, 2000). Partch was one of the first American pioneers of a completely new tradition in musicology, although he was certainly not the only iconoclast that broke away from the classical, European music traditions. On the other hand, the impressive work of Guerrino Mazzola, culminated in also a new, postwar tradition in the mathematical formalization of music (Mazzola, 2002, 2017). With the help of an advanced conceptual system derived from algebraic topology, Mazzola claims to have created a completely digitalized system of the entire realm of music, from the composers desk to the gestures of the music performers and the ears and brains of the listeners. In hindsight, Mazzola's mathematical construction is a bigger-than-life-itself phenomenon, it touches upon the Mind of its Creator: "After all, understanding God's composition, the material universe, cannot be approached without the most sophisticated tools as they have been elaborated in physics, chemistry, and molecular biology"(Mazzola, ibidem, preface, p. x).

But the (molecular) biology and chemistry, or the empirical sciences, don't occupy a dominant role in Mazzola's magnum opus. In fact, Mazzola's basic approach of a Denotator system, and its improvements, could also be seen as a smart retrieval system coupled to a pseudo-linear coding of a phenomenon which essentially is not linear. Consequently, all the information used for structuring a musical composition by means of a score on a two-dimensional page or screen, despite the complexity of its lexical appearance (such as the most advanced postmodern musical landscapes), can be broken down into a pseudo-linear, formal coding and navigation system for representation and retrieval of digitalized data. However, no digital music carrier can replace the experience of human interaction, as we may have learned from the COVID-19 pandemic.

Another argument is derived from the personal experience of playing music: if the flutist is capable of playing the tune, without paying attention to the notes on the score, while breathing the music in a well-balanced posture, in a flow (Le Roy, 1966), resulting from the experiencing of an inner time as well as a sense of duration in the music, and connecting with the inner time experienced by the listeners, then the performance doesn't detract from the music. Performing music is something completely different from playing consecutive notes in a row.

The remarks of Partch, regarding the strength of simplicity in poetry and its role in humanto-human connectivity, are equally opposed to the mathematical formalization as proposed by Mazzola. The de-humanization that builds upon the systematic distrust of all human senses and aspects of sensitivity, are well contrasted by the words of J.W. von Goethe (1749-1832) in his poem Prometheus (Goethe, 1774, 1932): "Cover thy spacious heavens, Zeus (...), this house was not raised by thee, leave me my hearth, whose kindly glow, by thee is envied (...)". Neither the new lords of digitalization have built this wonder of human existence, the capability of listening to one another, the hearth of our music.

\section{References}

Allaerts, W. (1992). Inquiry into the spatio-temporal contingency of cellular communication systems. Communication \& Cognition, 25(4), 277-294.

Allaerts, W. (1997). The Self and its biological function: Contrasts between Popper and Sartre. Logique \& Analyse, 158, 189-214.

Allaerts, W. (2017). When Teddy met Paulus (Tillich). Adorno on Kierkegaard again, 'das Ganze und die Innerlichkeit'. bi-logical, 6(2), 45-52.

Allaerts, W. (2019). Connectivity, continuity and distance norm in mathematical models for community ecology, epidemiology and multicellular pathway prediction. International Journal of Bioinformatics and Computational Biology, 4 (1), 1-10.

Allaerts, W. (2019). Into the Origins of the Inside-Outside Debate: Rediscovering Smell/Odor and Tracking the Steps of Nietzsche, Proust and Timothy Morton. Philosophy International Journal, 2(2), 000129. https://doi.org/10.23880/PhIJ-16000129

Allaerts, W. (2020). How to avoid speaking: The experience of the Chora in Derrida's Denials and in other paradigms of negativity. Philosophy International Journal, 3(1), 16000133. https://doi.org/10.23880/PHIJ-16000133

Allaerts, W. (2020). Phonemes, the use and abuse of speech-recognition systems. On a fractal topology of memes in a fractal world. Communication \& Cognition, 53(1-2), 3-32.

Allaerts, W. (2020). Turing's legacy and the conversion of genuine mathematical ideas in analogous application fields. Communication \& Cognition, 53(3-4), 123-152. 
Bach, J. S. (1722). Das Wohltemperirte Clavier oder Praeludia, und Fugen durch alle Tone und Semitonia, (...). Original Manuscript of Band 1, 1722 (source: Wikipedia Commons).

Barthes, R. (1964). Eléments de sémiologie. Communications 4 (fide Mazzola, 2017). https://doi.org/10.3406/comm.1964.1029

Bergson, H. (1968, 7th Ed). Durée et Simultanéité. A propos de la théorie d'Einstein. Bibliothèque de philosophie contemporaine. Paris: Presses Universitaires de France.

Cassirer, E. (1946). Language and Myth. New York: Dover Publications.

Dahlhaus, C. (1962). Die Natur der Musik und die Konsonanz. In: W. Wiora (Ed). Die Natur der Musik als Problem der Wissenschaft. Musikalische Zeitfragen, 10, 19-26. Kassel, Basel: Bärenreiter Verlag.

Dahlhaus, C., \& Eggebrecht, H. H. (1985). Was ist Musik? Wilhelmshaven et al: Heinrichshofen (fide Mazzola, 2017).

Dutch Physics Society. (2021). 'Dicht een deeltje'. Het standaardmodel in poëzie [in Dutch]. Contest at the occasion of centennial anniversary of Dutch Physics Society, September 2021. Nederlands Tijdschrift voor Natuurkunde, 87(9), 10.

Eggebrecht, H. H. (1993). Interpretation. In: "Das Paradox musikalischer Interpretation”, Symposium zum 80. Geburtstag von K. von Fischer, Univ. Zürich (fide Mazzola, 2017).

Eggebrecht, H. H. (1996). Musik im Abendland. München, Zürich: Piper (fide Mazzola, 2017).

Ellis, G., \& Silk, J. (2014). Defend the integrity of physics (Comment). Nature, 516, 321-323. https://doi.org/10.1038/516321a

Escher R., \& Escher M. C. (1985). Beweging en metamorfosen. een briefwisseling [in Dutch]. Amsterdam: Meulenhoff/Landshoff, pp. 28-38 (Letter of R. Escher to M.C. Escher of 20 February 1957).

Glucksmann, A. (1977). Les maîtres penseurs. Paris: Editions Grasset \& Fasquelle.

Goethe, J. W. (1774, 1932). Prometheus. In: Goethes Werke, Vermischte Gedichte (mit einer Einführung von Gerhart Hauptmann). Band I. Berlin: Verlag Th Knaur (1932 ed), 95-96.

Grothendieck, A., \& Dieudonné, J. (1971). Eléments de Géométrie Algébrique (1). Berlin, et al: Springer Verlag.

Hodges, A. (1983, 2000 Ed.). Alan Turing: The Enigma. (2000 edition with foreword by Douglas Hofstadter). New York: Walker \& Company.

Hofstadter, D. R. (1979). Gödel, Escher, Bach: an eternal golden braid. New York: Basic Books.

Jakobson, R. (1960). Linguistics and Poetics. In: T.A. Seboek (Ed). Style in Language. New York: Wiley (fide Mazzola, 2017).

Komparu, K. (1983). The Noh Theatre. New York: Weatherhill/Tankosha (fide Mazzola, 2017).

Le Roy, R. (1966). Traité de la Flûte. Historique, Technique et Pédagogique. Paris: Éditions Musicales Transatlantiques.

Lerdahl, F. (1987). Timbral Hierarchies. Contemporary Music Review, 2(1) (fide Mazzola, 2017). https://doi.org/10.1080/07494468708567056

Libbrecht, U. (2001). Burger van de wereld. Inleiding tot een wereld-beschouwing [in Dutch]. Eindhoven: Uitgeverij Damon.

Martinet, A. (1960). Eléments de Linguistique Générale. Paris: Colin (fide Mazzola, 2017).

Mazzola, G. (1989-1994). presto (Software manual). Zürich: SToA music.

Mazzola, G. (1990). Geometrie der Töne. Basel: Birkhauser. https://doi.org/10.1007/978-3-0348-7427-4

Mazzola, G. (2002, 2017, 2nd Ed.). The Topos of Music. I: Theory (Geometric Logic, Harmony, Counterpoint, Motives, Rhythm). Springer International Publishing AG (Part of Springer Nature). https://doi.org/10.1007/978-3-319-64364-9

Mazzola, G. (2017, 2nd Ed). Part XVI: Mathematics of Gestures. Par. 67. Mathematical Models of Creativity, pp. 1001-1080. In: The Topos of Music. Vol III: Gestures. Springer International Publishing AG (Part of Springer Nature). https://doi.org/10.1007/978-3-319-64481-3_12

Mazzola, G. (2017, 2nd Ed). Part XVIII: The Multiverse Perspective. Par. 75. Gesture Theory and String Theory, pp. 1173-1175. In: The Topos of Music. Vol III: Gestures. Springer International Publishing AG (Part of Springer Nature). https://doi.org/10.1007/978-3-319-64481-3_20

Molino, J. (1975). Fait Musical et Sémiologie de la Musique. Musique en Jeu 17 (fide Mazzola, 2017).

National Endowment for the Humanities (NEH)(USA). https://www.neh.gov

Nietzsche, F. (1988). Der Fall Wagner (Letter sent from Torino). In: P. D’Iorio (1975, Ed). Digitale Kritische Gesammtausgabe Werke und Briefe (eKGBW), digital version of German reference edition of Nietzsche's works, posthumous fragments, and correspondence edited by Giorgio Colli and Mazzina Montinari (Friedrich Nietzsche Werke, Kritische Gesamtausgabe (KGW), Berlin/New York, 1967 and Nietzsche Briefwechsel. Kritische Gesamtausgabe, Berlin/New York, de Gruyter, 1975).

Partch, H. (1940-1969, 1991, 2000 Ed.). Bitter Music. Collected Journals, Essays, Introductions and Librettos. Edited with an Introduction by Thomas McGeary. Urbana and Chicago: University of Illinois Press.

Putnam, H. (1975). The meaning of 'meaning'. Mind, Language and Reality. Philosophical Papers, 2, 215-271. Cambridge: Cambridge University Press. (See also W. Allaerts [2009]. Hilary Putnam and the inevitable deadlocks of functionalism. bi-logical, 2(2), 41-46). https://doi.org/10.1017/CBO9780511625251.014 
Reinhardt, F., \& Soeder, H. (1980). Atlas zur Mathematik. München: Deutscher Taschenbuch Verlag Gmbh \& Co.

Schoenberg, A. (1954, 1969 Ed). Structural Functions of Harmony. London and Boston: Faber and Faber.

Turing, A. M. (1939). Systems of logic based on ordinals. Proceedings of London Mathematics Society, series 2, 45, 161-228 https://doi.org/10.1112/plms/s2-45.1.161

van Houten, K., \& Kasbergen, M. (1985). Bach en het getal [in Dutch]. Zutphen: Uitgeverij Walburg Pers.

Winter, A. (2021). Zappa (Documentary). (Reconstructed from unpublished archive film material) Source: 2Doc.nl, www.ntr.nl, retrieved 18 August 2021.

Wittgenstein, L. (1922). Tractatus Logico-Philosophicus. New York: Harcourt, Brace \& Company, Inc. Woolf, H. B., et al. (1981)(Ed.). Webster's New Collegiate Dictionary. Springfield, MA: G. \& C. Merriam Company.

Zuckerkandl, V. (1957). Sound and symbol. Music and the external world. New York: Pantheon Books. https://doi.org/10.1515/9780691218366 